Article

\title{
Functional Expression, Purification and Identification of Interaction Partners of PACRG
}

\author{
Tiankai Liu ${ }^{1,+}$, Haizhou Zhao ${ }^{1,2,+}$, Shaofen Jian ${ }^{1}$, Shu Gong ${ }^{1}$, Sainan Li ${ }^{1}$, Yanhong Ma ${ }^{1}$, Jun Chen ${ }^{3, *}$ \\ and Wenhua Liu 1 ,*
}

check for updates

Citation: Liu, T.; Zhao, H.; Jian, S.; Gong, S.; Li, S.; Ma, Y.; Chen, J.; Liu, W. Functional Expression, Purification and Identification of Interaction Partners of PACRG. Molecules 2021, 26, 2308. https:// doi.org/10.3390/molecules26082308

Academic Editor: Yukio Yoneda

Received: 3 March 2021

Accepted: 12 April 2021

Published: 16 April 2021

Publisher's Note: MDPI stays neutral with regard to jurisdictional claims in published maps and institutional affiliations.

Copyright: (c) 2021 by the authors. Licensee MDPI, Basel, Switzerland. This article is an open access article distributed under the terms and conditions of the Creative Commons Attribution (CC BY) license (https:// creativecommons.org/licenses/by/ $4.0 /)$.
1 School of Life Sciences, Zhaoqing University, Zhaoqing 526061, China; 16tkliu@alumni.stu.edu.cn (T.L.); zhaohaizhou012@163.com (H.Z.); jianshaofen95@163.com (S.J.); Gongshu@zqu.edu.cn (S.G.); lisainan2001@sina.com.cn (S.L.); mayh6@mail2.sysu.edu.cn (Y.M.)

2 Department of Chemistry, City University of Hong Kong, Hong Kong 999077, China

3 Department of Pharmacognosy, School of Traditional Chinese Pharmacy, China Pharmaceutical University, No. 24 Tongjia Lane, Nanjing 210009, China

* Correspondence: chenj2002cpu@126.com (J.C.); wenhualiu@hotmail.com (W.L.)

+ These authors contributed equally to this work.

\begin{abstract}
PACRG (Parkin co-regulated gene) shares a bi-directional promoter with the Parkinson's disease-associated gene Parkin, but the physiological roles of PACRG have not yet been fully elucidated. Recombinant expression methods are indispensable for protein structural and functional studies. In this study, the coding region of PACRG was cloned to a conventional vector pQE80L, as well as two cold-shock vectors pCold II and pCold-GST, respectively. The constructs were transformed into Escherichia coli (DE3), and the target proteins were overexpressed. The results showed that the cold-shock vectors are more suitable for PACRG expression. The soluble recombinant proteins were purified with $\mathrm{Ni}^{2+}$ chelating column, glutathione S-transferase (GST) affinity chromatography and gel filtration. His 6 pull down assay and LC-MS/MS were carried out for identification of PACRG-binding proteins in HEK293T cell lysates, and a total number of 74 proteins were identified as potential interaction partners of PACRG. GO (Gene ontology) enrichment analysis (FunRich) of the 74 proteins revealed multiple molecular functions and biological processes. The highest proportion of the 74 proteins functioned as transcription regulator and transcription factor activity, suggesting that PACRG may play important roles in regulation of gene transcription.
\end{abstract}

Keywords: PACRG; cold-shock vectors; recombinant expression; purification; interaction partners

\section{Introduction}

PACRG (Parkin co-regulated gene) was cloned and identified in 2003 [1]. PACRG is approximately $600 \mathrm{~kb}$ in length and located on the antisense strain of the Parkin gene with a head-to-head arrangement. The two genes shares a bi-directional promoter and their transcription starting points are only $204 \mathrm{bp}$ away. The open reading frame (ORF) of PACRG encodes 257 amino acids with a molecular weight of about $30 \mathrm{kD}$. PACRG is highly conserved among various organisms, but no functional domain of PACRG has been identified yet. Parkin is an E3 ubiquitin ligase, and mutation or deletion of the Parkin gene is associated with autosomal recessive juvenile Parkinson's disease (ARJP) [2].

Previous studies reported that PACRG was capable of stabilizing microtubule structure via binding with $\alpha, \beta$-tubulin [3]. Deletion of PACRG caused a movement defect of flagellum and cilium, and this may be attributed to the factor that PACRG controls axonemal dynein-drive microtubule sliding [4,5]. Loss of PACRG led to male sterility in mice due to sperm motility deficiency [6]. These results described above implicate that PACRG plays an important role in microtubule-mediated movement [7]. In addition, PACRG is a component of Lewy bodies, and it is able to decrease the cell death induced by Pael-R which is a substrate of Parkin, suggesting the involvement of PACRG in neurodegeneration 
pathogenesis [8,9]. Moreover, variants in the bi-directional promoter region shared by PACRG and Parkin are associated with susceptibility to several infectious diseases, such as leprosy, tuberculosis, typhoid and paratyphoid fever, as well as leukemia and human astrocytic tumors [10-13]. Recently, Meschede et al. reported that PACRG protects against TNF-induced cell apoptosis, and this result may help to explain the association of PACRG and Parkin polymorphisms with susceptibility to these infectious diseases [14].

Until now, physiological functions and interaction partners of PACRG have been poorly elucidated. Under this situation, purified recombinant PACRG is indispensable for investigating its physiological roles. An E. coli prokaryotic expression system offers many advantages: simple culturing conditions, rapid bacterial growth, relative high-level expression and low cost. PACRG is easily degraded in eukaryotic cells [9], suggesting that PACRG is probably a hard-to-express protein. Li et al. first observed that expression of PACRG alone showed weak signal, while co-expression of MEIG1 with PACRG led to obvious enhancements of the protein levels in E. coli cells, indicating MEIG1 is able to stabilize PACRG [15]. Khan et al. reported a similar co-expression profile, and they first solved the structure of the PACRG/MEIG1 complex using the co-expression approach [16]. Additionally, their results showed that expression of GST-fused PACRG formed inclusion bodies by using the pGEX-6p1 vector [16]. These results confirm that it is difficult to achieve soluble and effective expression of PACRG. In this study, we attempt to develop a facile approach for soluble expression of PACRG by using a conventional vector $\mathrm{PQE} 80 \mathrm{~L}$, as well as two cold-shock vectors, pCold II and pCold-GST. Furthermore, we used the purified recombinant proteins to identify interaction partners of PACRG in HEK293T (Human embryonic kidney 293T) cell lysates, and this work could facilitate the understanding of the physiological roles of PACRG.

\section{Results}

\subsection{Recombinant Expression of PACRG}

Expression of pQE-PACRG was induced with $0.5 \mathrm{mM}$ isopropyl-D-thiogalactopyranoside (IPTG) for $1 \mathrm{~h}$ and $2 \mathrm{~h}$ at $37^{\circ} \mathrm{C}$, and for $2 \mathrm{~h}$ at $20^{\circ} \mathrm{C}$; while pCold-PACRG and pCold-GSTPACRG were induced with $0.5 \mathrm{mM}$ IPTG for $2 \mathrm{~h}$ at $20^{\circ} \mathrm{C}$. The supernatants of the cell lysates were subjected to SDS-PAGE and Coomassie brilliant blue (CBB) staining. However, no apparent overproduction band of $\mathrm{His}_{6}$-PACRG ( 31 kD) or His 6 -GST-PACRG ( $\left.\sim 60 \mathrm{kD}\right)$ could be discriminated in corresponding lanes in the gel (Figure 1A). These results suggested that expressions of PACRG in the three vectors are too weak to be observed by CBB staining.

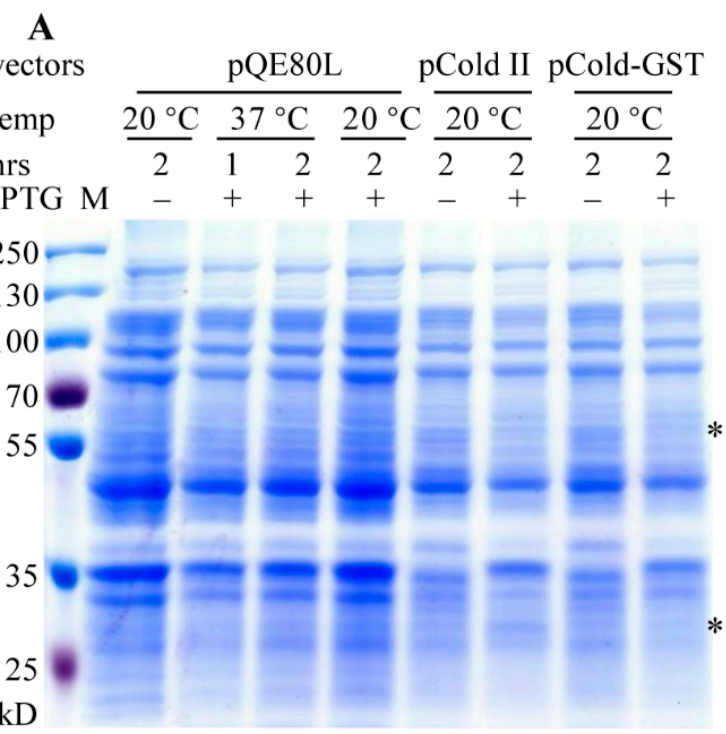

Figure 1. Cont. 


\section{B}

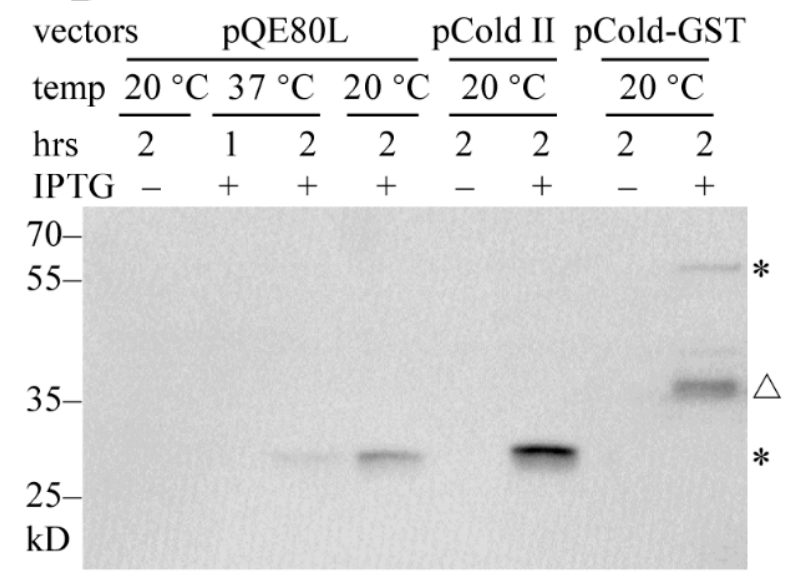

C

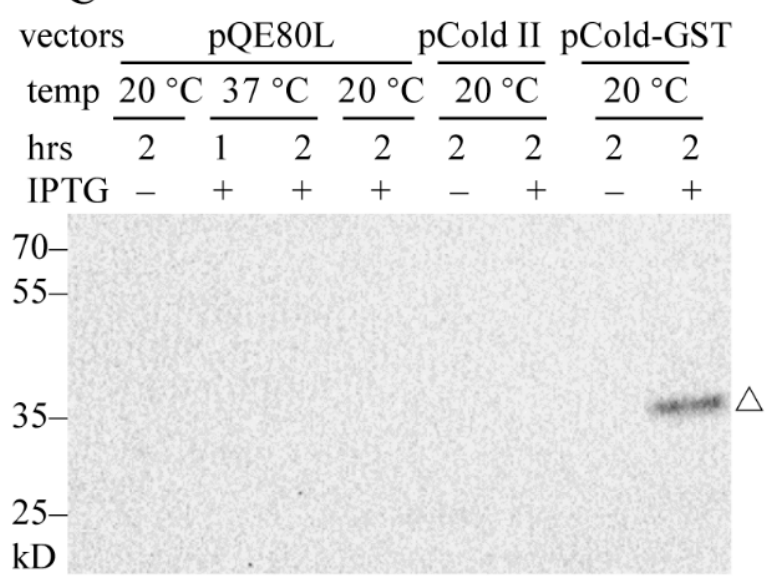

Figure 1. SDS-PAGE analysis of the expressions of recombinant PACRG (Parkin co-regulated gene). (A) Supernatant fractions of the cell lysates were carried on SDS-PAGE and Coomassie brilliant blue (CBB) staining. * denotes the expected migration location of $\sim 60 \mathrm{kD} \mathrm{His}{ }_{6}$-GST-PACRG (upper) and $\sim 31 \mathrm{kD} \mathrm{His}_{6}$-PACRG (lower); M, protein marker (Thermo). (B) WB analysis of recombinant PACRG in supernatant fractions of the cell lysates with PACRG Ab (Abcam). * denotes His ${ }_{6}$-GSTPACRG (upper) and His $_{6}$-PACRG (lower); $\triangle$ denotes degraded His ${ }_{6}$-GST-PACRG. (C) WB analysis of recombinant PACRG in pellet fractions of the cell lysates with the same $\mathrm{Ab}$. $\triangle$ denotes $\sim 38 \mathrm{kD}$ degraded His $_{6}$-GST-PACRG. 30 $\mu$ g protein was loaded for each sample.

We further detected the expressions of PACRG with western blot (WB). As shown in Figure 1B, recombinant PACRG was observed in the supernatant fractions of induced E. coli cell lysates. Plasmid pQE-PACRG showed a relative weak expression at $20{ }^{\circ} \mathrm{C}$ or $37^{\circ} \mathrm{C}$ for $2 \mathrm{~h}$, but not at $37^{\circ} \mathrm{C}$ for $1 \mathrm{~h}$. pCold-PACRG indicated an obvious expression of $\mathrm{His}_{6}$-PACRG at $20^{\circ} \mathrm{C}$ for $2 \mathrm{~h}$. While pCold-GST-PACRG showed a $\sim 60 \mathrm{kD} \mathrm{His}{ }_{6}$-GSTPACRG band, and several degraded fragments, among them a major $\sim 38 \mathrm{kD}$ degraded band. These data indicate that cold-shock vectors have advantages over PQE80L vector in PACRG overproduction.

We also measured the overproduction of PACRG in the pellet fractions of the cell lysates with WB. As shown in Figure 1C, no $\mathrm{His}_{6}$-PACRG or $\mathrm{His}_{6}$-GST-PACRG band is visible in the pellet fractions, except for a $\sim 38 \mathrm{kD}$ degraded $\mathrm{His}_{6}$-GST-PACRG band. These results suggest that the majorities of $\mathrm{His}_{6}$-PACRG and $\mathrm{His}_{6}$-GST-PACRG are soluble.

The cold-shock vector system has advantages for high-level expression of target protein under low temperature conditions, with increased solubility and minimal background protein production [17]. When the cultivation temperature is quickly dropped to $15^{\circ} \mathrm{C}$, cold-shock promoter such as CspA is strongly activated, resulting in a marked expression 
of cold-shock proteins. At the same time, growth of E. coli cells and synthesis of the host proteins are temporarily suppressed. Our results confirm that the cold-shock vectors are more appropriate than the conventional pQE80L vector for PACRG overexpression.

Synthesis of the $\mathrm{N}$-terminal $\mathrm{His}_{6}$-fused target protein will be terminated due to lack of histidine in the medium [18]. To ask if this is the putative reason for the weak expression of recombinant PACRG, we utilized the control vector pCold-GST, which also containing

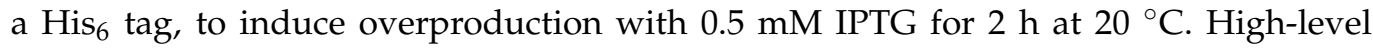
expression of GST was observed in CBB staining (Figure S1). These results indicate that both the bacterial system and the medium are appropriate for expression of these vectors.

\subsection{Optimizations of Expression Conditions of $p$ Cold-PACRG and $p$ Cold-GST-PACRG}

Next, we tested whether a lower temperature $15^{\circ} \mathrm{C}$ would benefit the expressions. Induction expression of pCold-PACRG was performed with $0.5 \mathrm{mM}$ IPTG for different durations at $20^{\circ} \mathrm{C}$ and $15^{\circ} \mathrm{C}$, and the supernatant fractions were subjected to WB. When using $20^{\circ} \mathrm{C}$ as growth temperature, the peak expression level appeared at $2 \mathrm{~h}$ of post induction (Figure 2A). At $15^{\circ} \mathrm{C}$ cultivation temperature, the maximum expression yields were observed at $4 \mathrm{~h}$ and $8 \mathrm{~h}$ of induction time. The optimal expression conditions for pCold-PACRG were found as cultivation at $15^{\circ} \mathrm{C}$ for $4 \mathrm{~h}$ or $8 \mathrm{~h}$ induction when using $0.5 \mathrm{mM}$ IPTG (Figure 2A).

A

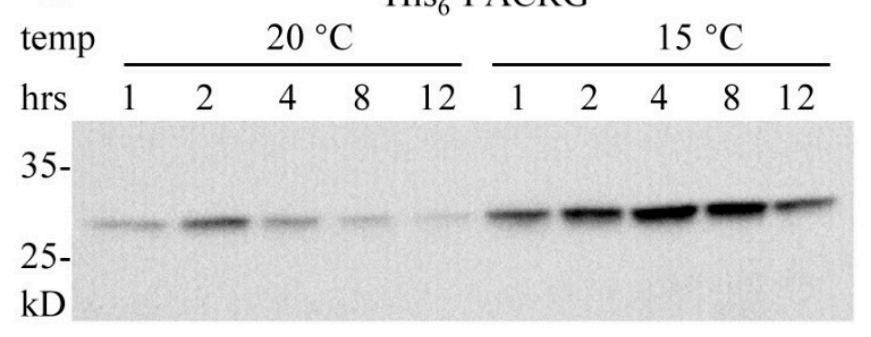

B His $_{6}$-GST-PACRG

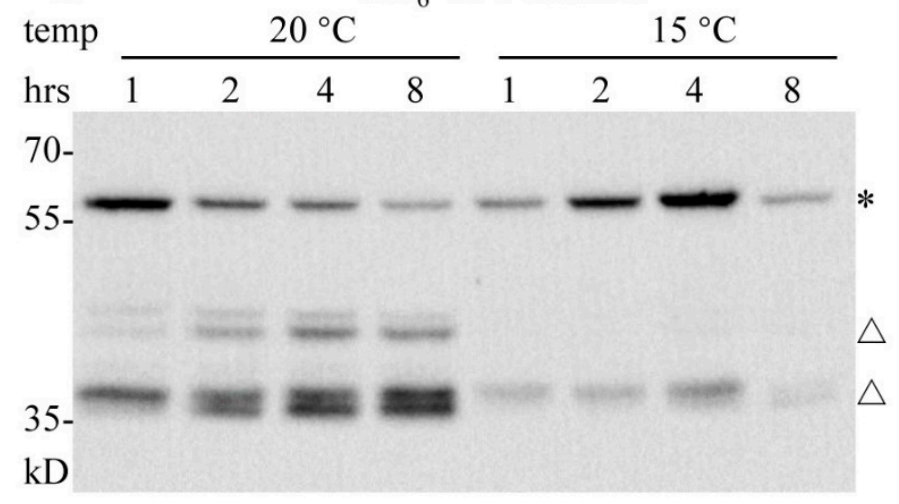

C $\mathrm{His}_{6}$-PACRG

IPTG $0.1 \quad 0.2 \quad 0.5 \quad 1.0$

$35-$

$25-$

$\mathrm{kD}$

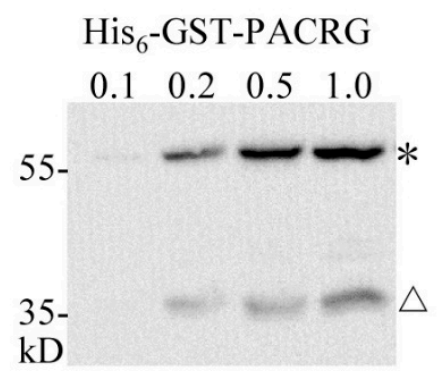

Figure 2. Optimization of expression conditions for pCold-PACRG and pCold-GST-PACRG. (A,B) WB analysis of pCold-PACRG and pCold-GST-PACRG expressions with $0.5 \mathrm{mM}$ IPTG for various induction 
durations at $20^{\circ} \mathrm{C}$ and $15^{\circ} \mathrm{C}$, respectively. (C) WB analysis of pCold-PACRG and pCold-GST-PACRG expressions induced with various concentrations of IPTG for $4 \mathrm{~h}$ at $15^{\circ} \mathrm{C}$. * denotes $\mathrm{His}_{6}$-GST-PACRG; $\triangle$ denotes degraded His $_{6}$-GST-PACRG.

Expression profiles of pCold-GST-PACRG were showed in Figure 2B. The $\sim 60 \mathrm{kD}$ full-length $\mathrm{His}_{6}$-GST-PACRG bands, along with several smaller degraded bands ( $\sim 45 \mathrm{kD}$ and $\sim 38 \mathrm{kD}$ ) were observed. The highest yields of full-length $\mathrm{His}_{6}$-GST-PACRG were produced at $20^{\circ} \mathrm{C}$ after $1 \mathrm{~h}$ of induction, and at $15^{\circ} \mathrm{C}$ for $4 \mathrm{~h}$ of induction. The degraded bands appeared mainly in the fractions of cultural cells at $20^{\circ} \mathrm{C}$. The optimal expression parameters for pCold-GST-PACRG were found as cultivation at $15^{\circ} \mathrm{C}$ for $4 \mathrm{~h}$ induction when using $0.5 \mathrm{mM}$ IPTG. Based on these results, lower temperature $15^{\circ} \mathrm{C}$ was more suitable for the expressions of the two vectors, and the peak yields of the two vectors showed no obvious difference (Figure 2A,B).

IPTG induction concentrations for the two plasmids were further investigated. As shown in Figure 2C, 0.2, 0.5 and 1.0 mM IPTG induced high yields for pCold-PACRG, while 0.5 and $1.0 \mathrm{mM}$ IPTG were optimal concentrations for pCold-GST-PACRG. Thus, we utilized 0.5 mM IPTG for the next experiments.

\subsection{Purifications of the Recombinant Proteins}

Expression products of pCold-PACRG were purified using two steps procedures involving $\mathrm{Ni}^{2+}$ chelating purification and gel filtration. As shown in Figure $3 \mathrm{~A}$ (left and right panel), the expected $\sim 31 \mathrm{kD} \mathrm{His}_{6}$-PACRG was eluted with $50 \mathrm{mM}$ imidazole, and confirmed by WB. After preliminary purification, the eluted fraction was concentrated and subsequently applied to gel filtration. The results showed a normal eluting profile for $\mathrm{His}_{6}$-PACRG, and the elution volume of the peak fraction was $\sim 59 \mathrm{~mL}$ (Figure 3B). In addition, our preliminary data indicated that the void volume of the column detected with blue dextran was $\sim 40 \mathrm{~mL}$, and the elution volumes of BSA $(66.4 \mathrm{kD})$ and cytochrome c $(12.5 \mathrm{kD})$ were $\sim 51 \mathrm{~mL}$ and $\sim 68 \mathrm{~mL}$, respectively. The elution volume of $\mathrm{His}_{6}$-PACRG $(\sim 59 \mathrm{~mL})$ laid in between the ones of BSA $(\sim 51 \mathrm{~mL})$ and cytochrome c $(\sim 68 \mathrm{~mL})$, suggesting that the estimated molecule weight of the purified His $_{6}$-PACRG matched its theoretical molecule weight $31 \mathrm{kD}$. These results indicated that $\mathrm{His}_{6}-\mathrm{PACRG}$ was a monomer in the elution fractions, and supported the conclusion that $\mathrm{His}_{6}$-PACRG was properly folded, to some content. The final yield of the purified $\mathrm{His}_{6}-\mathrm{PACRG}$ was established at $\sim 1.0 \mathrm{mg} / \mathrm{L}$ of Luria-Bertani (LB) culture medium.
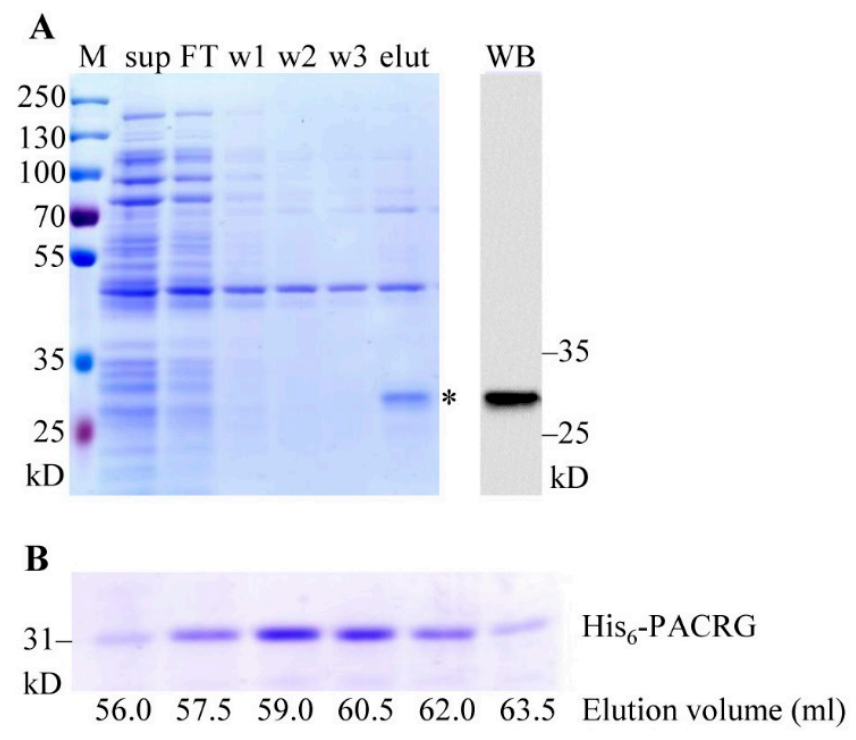

Figure 3. Cont. 


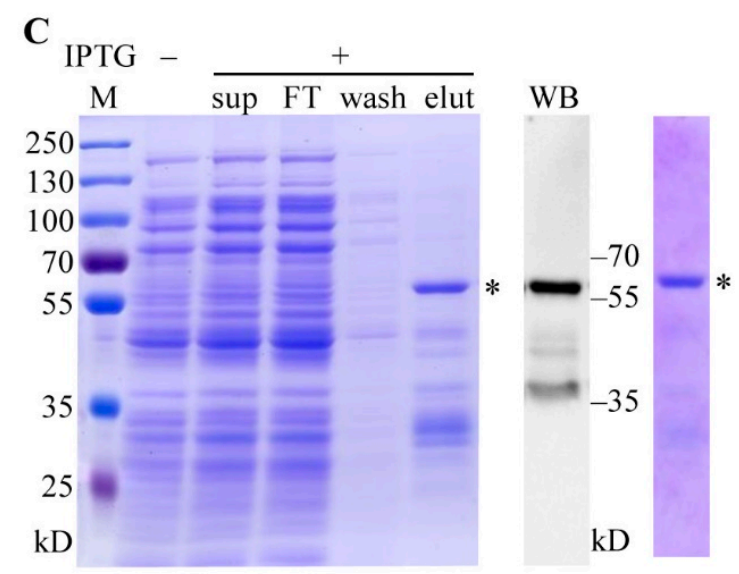

Figure 3. Purifications of $\mathrm{His}_{6}$-PACRG and $\mathrm{His}_{6}$-GST-PACRG. (A) Purification of pCold-PACRG expression product. Left panel: SDS-PAGE analysis and CBB staining of $\mathrm{Ni}^{2+}$ chelating purification fractions. Sup, supernatant; FT, flow through; w 1-3, fractions washed with sonication buffer, $2 \mathrm{mM}$ and $5 \mathrm{mM}$ imidazole, respectively; elut, fraction eluted with $50 \mathrm{mM}$ imidazole. Right panel: WB analysis of the eluted fraction with PACRG Ab. * denotes His 6 -PACRG. (B) Purification of His $_{6}{ }^{-}$ PACRG by gel filtration. $4 \mathrm{~mL}$ of $\mathrm{Ni}^{2+}$-charge purified $\mathrm{His}_{6}$-PACRG was loaded on the Sephacryl ${ }^{\mathrm{TM}}$ S-200 column, and eluted with the working buffer. The fractions were collected at $1.5 \mathrm{~mL} / \mathrm{tube}$ manually, and detected with SDS-PAGE and CBB staining. (C) Purification of pCold-GST-PACRG expression product. Left panel: CBB staining of GST affinity purification fractions. Sup, supernatant; FT, flow through; wash, fraction washed with sonication buffer; elut, fraction eluted with $20 \mathrm{mM}$ GSH. Middle panel: WB analysis of the eluted fraction with PACRG Ab. Right panel: CBB staining of gel filtration fraction. ${ }^{*}$ denote His $_{6}$-GST-PACRG. M, protein marker.

The recombinant $\mathrm{His}_{6}$-GST-PACRG was purified with GST affinity purification, followed by gel filtration. The $\sim 60 \mathrm{kD}$ full-length $\mathrm{His}_{6}-\mathrm{GST}-\mathrm{PACRG}$, along with various smaller size proteins, were eluted with $20 \mathrm{mM}$ GSH (Figure 3B, left panel). The recombinant $\mathrm{His}_{6}$-GST-PACRG was verified with WB (Figure 3B, middle panel), and further purified with gel filtration (Figure $3 \mathrm{~B}$, right panel). The elution volume of $\mathrm{His}_{6}$-GST-PACRG was $\sim 53 \mathrm{~mL}$, suggesting that the purified $\mathrm{His}_{6}$-GST-PACRG was a monomer in the elution fraction. Final yield of the protein was $\sim 1.5 \mathrm{mg} / \mathrm{L}$ of LB culture medium.

\subsection{Enriched Analysis of the PACRG Interaction Partners}

To detect PACRG-binding proteins in HEK293T cell lysates, pull down assays were carried out by using purified $\mathrm{His}_{6}$-PACRG and $\mathrm{His}_{6}$-GST-PACRG as baits. The total proteins bound to the baits, or the $\mathrm{Ni}^{2+}$-charged resin and His $_{6}$-GST were analyzed with SDS-PAGE (Figure 4), and identified by LC-MS/MS. Bound proteins of $\mathrm{Ni}^{2+}$-charged resin and purified His $_{6}$-GST were used as background subtraction for $\mathrm{His}_{6}-\mathrm{PACRG}$ and $\mathrm{His}_{6}-\mathrm{GST}-\mathrm{PACRG}$, respectively. A total number of 74 proteins in the two experiments were identified as PACRG interaction partners (Table S1). According to the $p$ value $<0.05$, gene ontology (GO) enrichment analysis (FunRich) of the 74 proteins revealed multiple molecular functions, including transcription factor activity containing ten proteins, transcription regulator activity consisting of eight proteins, along with other ten classifications of functions each of which contained one to five proteins, respectively (Table 1). 


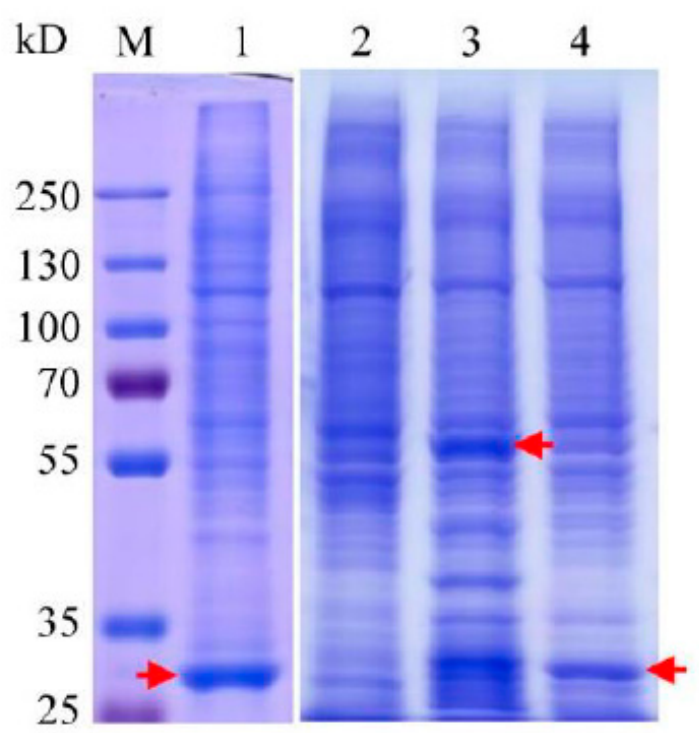

Figure 4. SDS-PAGE analysis of pull down assays using His $_{6}$-PACRG and His $_{6}$-GST-PACRG as baits. Lane 1: pull down assay using His $_{6}$-GST as bait. Arrow indicates the position of $\mathrm{His}_{6}$-GST. Lane 2: pull down assay of $\mathrm{Ni}^{2+}$-charged resin. Lane 3: pull down assay using $\mathrm{His}_{6}$-GST-PACRG as bait. Arrow indicates the position of $\mathrm{His}_{6}$-GST-PACRG. Lane 4: pull down assay using $\mathrm{His}_{6}-\mathrm{PACRG}$ as bait. Arrow indicates the position of $\mathrm{His}_{6}-\mathrm{PACRG}$.

Table 1. Function classifications of the Parkin co-regulated gene (PACRG) interaction partners.

\begin{tabular}{cccc}
\hline S. No. & Molecular Function & Gene Names & No. of Genes \\
\hline & -Value \\
1 & Transcription factor activity & UBP1; SMAD4; IRF3; RSRC2; FOXC1; DCP1A; HEXIM1; & 10 \\
2 & Heat shock protein activity & YY1; BCLAF1; MNX1 & 0.0014 \\
3 & Receptor signaling complex scaffold activity & HSPD1; HSPA8 & 2 \\
4 & Chaperone activity & STAM2; IRS4; SNTB2; PDLIM5; HOMER1 & 5 \\
5 & RNA binding & HSPA1A; HSPA5 & 2 \\
6 & Transcription regulator activity & SMAD3; TRIP4; FUBP1; SNW1; MID1; ZNF24; POLR3C; & 0.0048 \\
7 & Intracellular transporter activity & SAP30BP & 0.013 \\
8 & Structural constituent of cytoskeleton & ATG16L1 & 0.013 \\
9 & ATP binding & TUBB2B; TUBGCP4; CCDC6 & 0.014 \\
10 & GTP binding & ABCD3 & 3 \\
11 & Exonuclease activity & SEPT9 & 0.015 \\
12 & Enzyme regulator activity & EXD2 & 0.015 \\
\hline
\end{tabular}

Analysis of the 74 proteins disclosed diverse types of significantly enriched biological processes, including regulation of nucleotide metabolism containing 26 proteins, protein metabolism consisting of nine proteins, cell proliferation with two proteins (Table 2). Beyond that, nuclear organization and biogenesis, neurotransmitter transport, amino acid and derivative metabolism, cell surface receptor linked signal transduction, regulation of immune response and regulation of translation, each of which contained one protein, were also identified as significant biological processes (Table 2).

Enrichment analysis of the 74 proteins revealed a large number of significant biological pathways. Figure 5 showed the 12 biological pathways with the lowest $p$ values. The four main ones include sphingosine 1-phosphate (S1P) pathway, TRAIL signaling pathway, metabolism of mRNA, and ALK1 pathway. 
Table 2. Classifications of biological processes in relation to the PACRG interaction partners.

\begin{tabular}{|c|c|c|c|c|}
\hline S. No. & Biological Process & Gene Names & No. of Genes & $p$-Value \\
\hline 1 & Regulation of nucleotide metabolism & $\begin{array}{c}\text { SMAD3; TRIP4; FUBP1; SNW1; MID1; ZNF24; } \\
\text { POLR3C; UBP1; SMAD4; IRF3; FOXC1; DCP1A; } \\
\text { HEXIM1; YY1; BCLAF1; MNX1; DHX15; IGF2BP2; } \\
\text { CSTF2; RNPS1; SF1; EXD2; HIST2H2BF; ZNF787; } \\
\text { ORC2; SETMAR }\end{array}$ & 26 & $9.86 \times 10^{-6}$ \\
\hline 2 & Nuclear organization and biogenesis & TMPO & 1 & 0.0039 \\
\hline 3 & Cell proliferation & RSRC2; SEPT9 & 2 & 0.0099 \\
\hline 4 & Neurotransmitter transport & STXBP1 & 1 & 0.015 \\
\hline 5 & Amino acid and derivative metabolism & ALDH18A1 & 1 & 0.015 \\
\hline 6 & Protein metabolism & $\begin{array}{l}\text { HSPD1; HSPA8; HSPA1A; HSPA5; MID1; PSMD4; } \\
\text { TRIM11; USP39; USP35 }\end{array}$ & 9 & 0.030 \\
\hline 7 & $\begin{array}{l}\text { Cell surface receptor linked signal } \\
\text { transduction }\end{array}$ & SMAD1 & 1 & 0.030 \\
\hline 8 & Regulation of immune response & HSPD1 & 1 & 0.030 \\
\hline 9 & Regulation of translation & IGF2BP2 & 1 & 0.049 \\
\hline
\end{tabular}

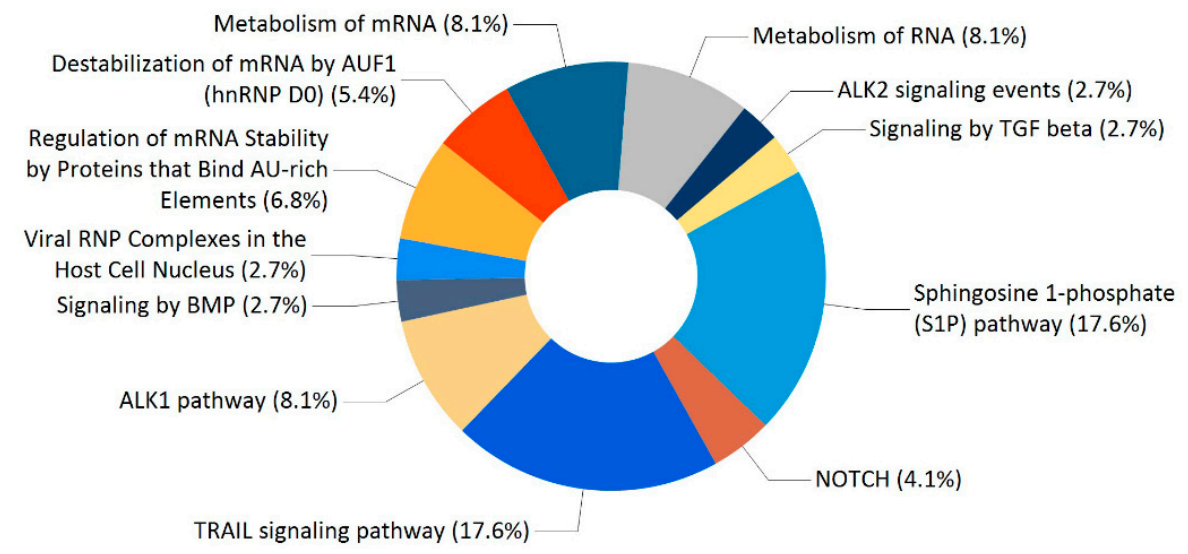

Figure 5. Classifications of biological pathways for the 74 proteins.

\section{Discussion}

In the present study we performed the recombinant expressions of PACRG using a conventional vector and two cold-shock vectors pCold II and pCold-GST. Our results showed that the cold-shock vectors are more suitable for PACRG expression, and the majorities of the recombinant PACRG were soluble. Moreover, a lower temperature of $15^{\circ} \mathrm{C}$ gave higher yields, suggesting that this result may be attributed to inhibition degradation of the recombinant proteins in the host bacteria at the lower temperature (Figure 2). Previous investigation indicated that recombinant expression of PACRG alone resulted in little or no signal, while expression of GFP-fused PACRG formed inclusion bodies [16]. The pColdGST vector was developed for improving expression of low solubility proteins and unstable proteins, and it has been successfully applied for expressions of multiple proteins $[19,20]$. Our data showed that the majority of the recombinant His $_{6}$-GST-PACRG was soluble by using the vector pCold-GST, confirming that the cold shock vector could increase the solubility of recombinant proteins. After induction expressions, the recombinant $\mathrm{His}_{6}{ }^{-}$ PACRG and $\mathrm{His}_{6}$-GST-PACRG were further purified with $\mathrm{Ni}^{2+}$ chelating column, GST affinity chromatography and gel filtration, and the two purified proteins were obtained at yield levels of $\sim 1.0 \mathrm{mg} / \mathrm{L}$ and $\sim 1.5 \mathrm{mg} / \mathrm{L}$ of LB culture medium, respectively. The yields were not high, but at a reasonable level. In addition, our data indicated that His $_{6}$-GSTPACRG tended to degrade to smaller fragments, especially at $20^{\circ} \mathrm{C}$ growth condition (Figure 2B). GST itself expressed with pCold-GST was stable until $12 \mathrm{~h}$ post induction at $20^{\circ} \mathrm{C}$ (Figure S1), so the degradation of $\mathrm{His}_{6}$-GST-PACRG should be due to cleavages of PACRG. Based on the molecular weight calculations, the $\sim 38 \mathrm{kD}$ degraded $\mathrm{His}_{6}$-GSTPACRG should contain a $\sim 30 \mathrm{kD} \mathrm{His}_{6}$-GST, and a $\sim 8 \mathrm{kD} \mathrm{N}$-terminal fragment of PACRG which is a divergent region in PACRG orthologs [3]. Moreover, the $\sim 38 \mathrm{kD}$ degraded 
His $_{6}$-GST-PACRG tended to be insoluble in the lysate (Figure 1C). Considering that PACRG is an aggregated component of Lewy bodies [8], the question of whether the N-terminal divergent region of PACRG is responsible for its aggregation in Lewy bodies may deserve to be further investigated.

Pull down assay and LC-MS/MS identified a total of 74 potential interaction partners of PACRG, including several identified previously interactors, namely HSPA1A, HSPA8 and TUBB2B, which is a member of TUBB isforms (Table S1) [8]. Enrichment analysis showed that a higher proportion of the PACRG interaction partners functioned as transcription regulator and transcription factor activity, suggesting that PACRG may play an important role in regulation of gene transcription (Table 1). Transcriptional regulation activities of PACRG have been reported previously in studies in which PACRG promoted nuclear factor $\kappa \mathrm{B}(\mathrm{NF}-\mathrm{\kappa B})$ activation [14], and acted upstream of the transcription factor DAF-16 [21]. Furthermore, Parkin, whose gene shares a bi-directional promoter with $P A C R G$, has been shown multiple transcriptional regulation activities [22-24]. Therefore, these transcription regulators and transcription factors could be attractive targets for deeper functional studies of PACRG.

Three interactors including TUBB2B, TUBGCP4 and CCDC6, which function as structural constituent of cytoskeleton, were also identified (Table 1). PACRG is well known to play important roles in stabilizing microtubule structure via binding with $\alpha, \beta$-tubulin [3], whereas TUBGCP4 and CCDC6 were newly found to be potential interaction partners of PACRG in this study. However, these probable interactions require further confirmation through in vitro and in vivo experiments.

Enrichment analysis indicated that the 74 proteins were involved in diverse significant biological processes, among which regulation of nucleotide metabolism and protein metabolism were the first two proportional ones (Table 2). The sublist of regulation of nucleotide metabolism contained 26 proteins, which consisted of most proteins functioning as transcription factor activity, RNA binding and transcription regulator activity (Tables 1 and 2). The biological process of protein metabolism contained nine members, among which the four proteins HSPD1, HSPA8, HSPA1A and HSPA5 functioned as heat shock protein activity or chaperone activity, and the remaining five proteins served as a ubiquitination pathway enzyme or a ubiquitin receptor (Tables 1 and 2). Previous investigation showed that PACRG served as an adaptor protein, and facilitated HOIP-dependent linear ubiquitination [14]. Given the fact that genes driven by bidirectional promoters cooperate in common pathways and Parkin is an E3 ubiquitin ligase [25,26], so PACRG may have more functions associated with ubiquitin-dependent protein catabolic process. In this study, five ubiquitination pathway-related proteins, namely MID1, PSMD4, TRIM11, USP39 and USP35, were identified (Table 2). These findings should be helpful for further functional clarification related to PACRG.

Enrichment analysis showed that the most significant enriched biological pathways for the 74 proteins are sphingosine 1-phosphate (S1P) pathway and TRAIL signaling pathway (Figure 5). S1P is a bioactive lipid second messenger that regulates diverse biological processes, and S1P pathway has been implicated in the pathogeneses of autoimmune disease, cancer and other diseases [27-29]. Tumor necrosis factor (TNF)-related apoptosis-inducing ligand (TRAIL), a member of the large TNF superfamily, selectively triggers apoptosis in tumor cells, but not normal cells [30,31]. S1P pathway and TRAIL signaling pathway have been extensively investigated as potential targets for treatments of multiple diseases. It has been reported that the bi-directional promoter region of PACRG and Parkin genes is associated with susceptibility to leprosy and several types of cancer, but the underlying mechanisms are still poorly elucidated [10,13,32-36]. Leprosy is a chronic infectious disease caused by Mycobacterium leprae, and clinical manifestations of leprosy are strongly correlated with the host's immune responses [37]. Given the fact that S1P pathway and TRAIL signaling pathway are associated with the pathogeneses of autoimmune disease and cancer, therefore, further studies on the roles of PACRG related to the two pathways may 
help to elucidate the association of PACRG and Parkin polymorphisms with an increased susceptibility to leprosy and cancer.

Overall, in the current study, we have developed a facile approach for soluble expression of PACRG by using the cold-shock vectors, and this method would be very helpful for further research. PACRG consists of an $\mathrm{N}$-terminal divergent region and several conserved regions [3], and functions of these regions are still far from clear. This approach could be applied to express these fragments of PACRG, and identify the interactors of them by combining a pull down assay. Subsequent comparative analysis on the interactors of PACRG and these fragments could facilitate our understanding the different roles of these regions. In addition, a total number of 74 proteins have been identified as potential interaction partners of PACRG in our study, and a higher proportion of the partners function as transcription regulator and transcription factor. Most of the transcription regulators and the transcription factors execute complex physiological functions. For example, transcription factor YY1 (Yin Yang 1) is able to act as both a transcriptional activator and repressor, which depend on various post-translational modifications of $Y Y 1$ and different co-factors binding with YY1 [38-40]. YY1 plays important roles in neuroprotective pathways associated with ischemic damage, Parkinson's and Alzheimer's disease, and acts as a tumor suppressor or stimulator [38,41]. Thus, whether and how PACRG interplays with these transcription regulators and transcription factors, such as YY1, would be attractive research topics. Moreover, the identification of five ubiquitination pathway-related proteins, including two ubiquitin ligases MID1 and TRIM11, two deubiquitinating enzymes USP35 and USP39, as well as the proteasome regulatory subunit PSMD4, is also of interest. Given the facts that PACRG has no known catalytic activity and it serves as an adaptor protein to facilitated HOIP-dependent ubiquitination [14], we speculate that PACRG may play an adaptor role in the ubiquitination pathways associated with the five partners. Additional experiments need to be performed to verify this hypothesis. Taken together, the identification of interaction partners provide intriguing candidate targets towards understanding the role of PACRG.

\section{Materials and Methods}

\subsection{Construction of Expression Plasmids $p Q E-P A C R G, p$ Cold-PACRG and $p$ Cold-GST-PACRG}

The full-length coding sequence of human PACRG (GeneBank NO. AF546872) was amplified by PCR using cDNA reversed from the total RNA of HEK293T cells, and cloned into Tag3B vector. The coding sequence was then cleaved with BamH I and Hind III from Tag3B-PACRG plasmid and subcloned into the expression vectors pQE-80L, pCold II, and pCold-GST in frame, respectively. The entire inserted sequence was verified by nucleotide sequencing. The plasmids were transformed separately into E. coli BL21(DE3) strain for effective protein expression. All the three expression plasmids harbor a $\mathrm{His}_{6}$ tag in their $\mathrm{N}$-terminal to facilitate $\mathrm{Ni}^{2+}$ chelating purification, while pCold-GST-PACRG contains an additional GST tag following its $\mathrm{His}_{6}$ tag.

\subsection{Prokaryotic Expression of $p Q E-P A C R G$, $p$ Cold-PACRG and $p$ Cold-GST-PACRG}

Each clone of the three plasmids was grown at $37^{\circ} \mathrm{C}$ in LB broth containing $100 \mathrm{mg} / \mathrm{L}$ ampicillin under shaking overnight, and the night cultures were diluted $1 / 50$ to $10 \mathrm{~mL}$ fresh medium and allowed to grow at $37^{\circ} \mathrm{C}$ to middle log phase $\left(\mathrm{OD}_{600}\right.$ between 0.5 to 0.8$)$. Different treatments were carried out for expressions of the three plasmids. Expression of PQE-PACRG was induced with $0.5 \mathrm{mM}$ IPTG for 1 and $2 \mathrm{~h}$ at $37{ }^{\circ} \mathrm{C}$, and for $2 \mathrm{~h}$ at $20^{\circ} \mathrm{C}$. Expressions of the other two plasmids pCold-PACRG and pCold-GST-PACRG were performed cold-shock treatment prior to IPTG induction, namely, the medium was cooled in ice-water mixture to drop the medium temperature to $15^{\circ} \mathrm{C}$, and kept an additional $30 \mathrm{~min}$. After cold-shock treatment, expressions of pCold-PACRG and pCold-GST-PACRG were induced with several different combinations, including various IPTG concentrations $(0.1,0.2,0.5,1 \mathrm{mM})$ combined with different growth temperature (at $20^{\circ} \mathrm{C}$ and $15{ }^{\circ} \mathrm{C}$ ) for $1,2,4,8$ or $12 \mathrm{~h}$ (see "results and discussion" for details). The cells were harvested 
by centrifugation at $5000 \times g$ for $10 \mathrm{~min}$ at $4{ }^{\circ} \mathrm{C}$, and the centrifugated pellets were then collected for detection of expression levels.

\subsection{Purification of Recombinant Proteins}

After detection of the protein expression levels, only the two cold-shock plasmids were subjected to large-scale expression. Each protein was typically expressed in $300 \mathrm{~mL}$ LB culture medium with $0.5 \mathrm{mM}$ IPTG induction for $4 \mathrm{~h}$ at $15^{\circ} \mathrm{C}$. After centrifugation, the collected cells were resuspended in ice-chilled sonication buffer (PBS supplied with $150 \mathrm{mM}$ sodium chloride $(\mathrm{NaCl}), 1 \%$ Triton $\mathrm{X}-100,1 \mathrm{mM}$ phenylmethylsulfonyl fluoride (PMSF), $0.5 \mathrm{mM}$ EDTA, pH 7.0) and sonicated on ice at $300 \mathrm{~W}$ (total time $10 \mathrm{~min} .3 \mathrm{~s}$ on, $5 \mathrm{~s}$ off). Then, the lysates were centrifugated at $10,000 \times g$ for $30 \mathrm{~min}$ at $4{ }^{\circ} \mathrm{C}$, and the supernatants were collected for purification. Briefly, after washing with sonication buffer three times, the $\mathrm{Ni}^{2+}$-charged resin (Beyotime, Shanghai, China) was mixed with the supernatant. Then, the mixture was incubated at $4{ }^{\circ} \mathrm{C}$ with rotation for $2 \mathrm{~h}$. After loading to a $3 \mathrm{~mL}$ column, the resin-supernatant reaction was subsequently washed with sonication buffer, $2 \mathrm{mM}$ and $5 \mathrm{mM}$ imidazole. The bound proteins were eluted with $50 \mathrm{mM}$ imidazole (in sonication buffer). While the procedures of GST affinity purification were similar to that of $\mathrm{Ni}^{2+}$-charged purification, instead of washing with sonication buffer, and elution with $20 \mathrm{mM}$ glutathione (GSH, in $50 \mathrm{mM}$ Tris- $\mathrm{HCl}, 150 \mathrm{mM} \mathrm{NaCl}, 1 \mathrm{mM}$ PMSF, 1 mM EDTA, pH 8.0).

The eluted fractions from $\mathrm{Ni}^{2+}$ chelating and GST affinity purification were applied to Sephacryl ${ }^{\mathrm{TM}}$ S-200 (GE Healthcare) gel filtration for further purification. A column $(1.6 \mathrm{~cm} \times 50 \mathrm{~cm})$ filled with S-200 was equilibrated with working buffer $(50 \mathrm{mM}$ Tris- $\mathrm{HCl}$, $150 \mathrm{mM} \mathrm{NaCl}, 1 \mathrm{mM}$ PMSF, $1 \mathrm{mM}$ EDTA, pH7.0). The fraction ( 4 mL) was filtered with a $0.45 \mu \mathrm{m}$ filter membrane, loaded onto the column, then eluted with the working buffer. PACRG-containing fractions were pooled, concentrated, and stored at $-80^{\circ} \mathrm{C}$.

\subsection{SDS-PAGE and Western Blot}

Sodium dodecyl sulfate-polyacrylamide gel electrophoresis (SDS-PAGE) was carried out on $10 \%$ polyacrylamide gel, and the gel was stained with Coomassie brilliant blue (CBB) R-250. Western blot (WB) experiments were performed with $\mathrm{N}$-terminal specific PACRG antibody (Ab, 1:1000, Abcam).

\subsection{His-Tag Pull Down Assay}

HEK293T (Human embryonic kidney 293T) cell was previously used for the identification of PACRG-binding proteins with an immunoprecipitation approach [8]. Alternatively, in this study, we performed pull down assays using $\mathrm{His}_{6}$-PACRG and $\mathrm{His}_{6}$-GST-PACRG as baits to detect interactors of PACRG in HEK293T cell lysates. Briefly, after buffer exchanged with $10 \mathrm{kD}$ ultrafilters, the purified $\mathrm{His}_{6}$-PACRG and His ${ }_{6}$-GST-PACRG were coupled separately to $\mathrm{Ni}^{2+}$-charged resins for $2 \mathrm{~h}$ at $4{ }^{\circ} \mathrm{C}$ with rotation. Then, the protein-resin mixtures were incubated with supernatants of HEK293T cell lysates for an additional $2 \mathrm{~h}$. After incubation, the $\mathrm{Ni}^{2+}$-charged resins were washed three times with $5 \mathrm{mM}$ imidazole and then boiled in $2 \times$ SDS loading buffer for $5 \mathrm{~min}$. The bound fractions were subjected to SDS-PAGE and CBB staining.

\subsection{LC-MS/MS Analysis}

The bound fractions in Section 4.5 were subjected to $8 \%$ SDS-PAGE concentrated gel. After 20 min running, the protein-bromophenol blue bands, which contained the total bound proteins, were excised separately, followed by decolorization in $50 \% \mathrm{MeOH} / 50 \mathrm{mM}$ $\mathrm{NH}_{4} \mathrm{HCO}_{3}$, reduction in $25 \mathrm{mM}$ DTT/50 $\mathrm{mM} \mathrm{NH}_{4} \mathrm{HCO}_{3}$, alkylation in $55 \mathrm{mM} \mathrm{IAA} / 50 \mathrm{mM}$ $\mathrm{NH}_{4} \mathrm{HCO}_{3}$, and digestion with trypsin at $37^{\circ} \mathrm{C}$ overnight. Digestion products were extracted using $0.1 \%$ formic acid, $2 \%$ acetonitrile. After desalination, peptides were separated by a reverse-phase column (Acclaim PepMap $15 \mathrm{~cm} \times 75 \mu \mathrm{m}, \mathrm{C} 18,3 \mu \mathrm{m}, 100 \mathrm{~A}$, Thermo) using acetonitrile gradient containing $0.1 \%$ formic acid at a flow rate of $0.3 \mu \mathrm{L} / \mathrm{min}$ for 
$65 \mathrm{~min}$. Mass spectrometry was achieved using a Thermo Scientific Q Exactive. Mascot generic format (MGF) sample files were then analyzed using Mascot software. Peptides of greater than $95.0 \%$ probability were accepted. Each bound protein of $\mathrm{His}_{6}$-PACRG and $\mathrm{His}_{6}$ GST-PACRG was obtained if either of the following criteria were met: number of detected peptides in the pull down sample $\geq 2$ and no detected peptide in the corresponding control [42]; number of detected peptides in the sample $\geq 3$ and the ratio of peptides number of sample/control $\geq 2$ [43]. Bound proteins of $\mathrm{Ni}^{2+}$-charged resin and purified $\mathrm{His}_{6}$-GST were used as the control for $\mathrm{His}_{6}$-PACRG and $\mathrm{His}_{6}$-GST-PACRG, respectively. Bound proteins that were present in both $\mathrm{His}_{6}$-PACRG and $\mathrm{His}_{6}$-GST-PACRG pull down experiments were accepted as PACRG interaction partners. The obtained proteins were searched against the Universal Protein Resource (UniProt) database. The function classifications of the proteins were performed with FunRich (functional enrichment) software [44].

\subsection{Cell Culture of HEK293T}

HEK293T cells were grown in DMEM medium supplemented with $10 \%$ fetal bovine serum and penicillin-streptomycin solution. The cells were lysed for $20 \mathrm{~min}$ on ice with cold lysis buffer (same as sonication buffer). The lysates were centrifuged at 20,000 $\times g$ for $10 \mathrm{~min}$ at $4{ }^{\circ} \mathrm{C}$, and the supernatant fractions were applied to pull down assay.

\section{Conclusions}

In this work, we developed approaches for the soluble expressions of $\mathrm{His}_{6}$-PACRG and $\mathrm{His}_{6}$-GST-PACRG using the two cold-shock vectors. The recombinant proteins were purified with $\mathrm{Ni}^{2+}$ column, GST affinity chromatography and gel filtration, and the two purified proteins were obtained at yields of $\sim 1.0 \mathrm{mg} / \mathrm{L}$ and $\sim 1.5 \mathrm{mg} / \mathrm{L}$ of LB culture medium, respectively. Then, we used the purified proteins as baits to isolate and identify functional partners of PACRG. Overall 74 proteins were identified as interaction partners of PACRG, among which 18 proteins function as transcription regulator and transcription factor activities, suggesting that PACRG may play important roles in regulation of gene transcription. In addition, five ones of the 74 interactors are ubiquitination pathway-related proteins, implicating involvement of PACRG in ubiquitin-dependent protein metabolism process. Finally, the N-terminal divergent region of PACRG tended to be insoluble in E. coli, and whether this region accounts for the aggregation of PACRG in Lewy bodies may deserve to be further elucidated.

Supplementary Materials: The following are available online, Figure S1: Expression profiles of pCold-GST without or with $0.5 \mathrm{mM}$ IPTG induction for various durations at $20^{\circ} \mathrm{C}$, Table S1: List of the 74 potential interaction partners of PACRG.

Author Contributions: W.L. conceived the study, performed experiments, analyzed data and wrote the manuscript. T.L., H.Z., S.J. and S.G. performed experiments. S.L. and Y.M. validated data. J.C. conceived the study and reviewed the manuscript. All authors have read and agreed to the published version of the manuscript.

Funding: This work was supported by the National Nature Science Foundation of China (31271124), and Innovation Team Project of Department of Education of Guangdong Province (2015KCXTD032).

Institutional Review Board Statement: Not applicable.

Informed Consent Statement: Not applicable.

Data Availability Statement: Not applicable.

Acknowledgments: We thank Jian Feng (State University of New York at Buffalo, USA) for the construct Tag3B-PACRG. We thank Aidong Han (Xiamen University, China) and Dingyuan Ma (Nanjing Maternity and Child Health Care Hospital, China) for their assistance in revising the manuscript.

Conflicts of Interest: The authors declare that they have no conflict of interest. 


\section{References}

1. West, A.B.; Lockhart, P.J.; Ofarell, C.; Farrer, M.J. Identification of a Novel Gene Linked to Parkin via a Bi-directional Promoter. J. Mol. Biol. 2003, 326, 11-19. [CrossRef]

2. Kitada, T.; Asakawa, S.; Hattori, N.; Matsumine, H.; Yamamura, Y.; Minoshima, S.; Yokochi, M.; Mizuno, Y.; Shimizu, N. Mutations in the Parkin Gene Cause Autosomal Recessive Juvenile Parkinsonism. Nature 1998, 392, 605-608. [CrossRef]

3. Ikeda, T. Parkin-co-regulated Gene (PACRG) Product Interacts with Tubulin and Microtubules. FEBS Lett. 2008, 582, 1413-1418. [CrossRef] [PubMed]

4. Dawe, H.R.; Farr, H.; Portman, N.; Shaw, M.K.; Gull, K. The Parkin Co-regulated Gene Product, PACRG, is an Evolutionarily Conserved Axonemal Protein That Functions in Outer-doublet Microtubule Morphogenesis. J. Cell Sci. 2005, 118, 5421-5430. [CrossRef]

5. Mizuno, K.; Dymek, E.E.; Smith, E.F. Microtubule Binding Protein PACRG Plays a Role in Regulating Specific ciliary Dyneins during Microtubule Sliding. Cytoskeleton 2016, 73, 703-711. [CrossRef]

6. Lorenzetti, D.; Bishop, C.E.; Justice, M.J. Deletion of the Parkin Coregulated Gene Causes Male Sterility in the Quaking viable Mouse Mutant. Proc. Natl. Acad. Sci. USA 2004, 101, 8402-8407. [CrossRef] [PubMed]

7. Zhao, H.Z.; Li, J.; Ma, Y.H.; Liu, W.H. Research Progress of Parkin Co-regulated Gene. Chin. Pharmacol. Bull. 2018, 34, 1333-1336.

8. Imai, Y.; Soda, M.; Murakami, T.; Shoji, M.; Abe, K.; Takahashi, R. A Product of the Human Gene Adjacent to Parkin is a Component of Lewy Bodies and Suppresses Pael Receptor-induced Cell Death. J. Biol. Chem. 2003, 278, 51901-51910. [CrossRef]

9. Taylor, J.M.; Song, Y.J.; Huang, Y.; Farrer, M.J.; Delatycki, M.B.; Halliday, G.M.; Lockhart, P.J. Parkin Co-regulated Gene (PACRG) is Regulated by the Ubiquitin-proteasomal System and is Present in the Pathological Features of Parkinsonian Diseases. Neurobio. Dis. 2007, 27, 238-247. [CrossRef] [PubMed]

10. Mira, M.T.; Alcaïs, A.; Nguyen, V.T.; Moraes, M.O.; Di Flumeri, C.; Vu, H.T.; Mai, C.P.; Nguyen, T.H.; Nguyen, N.B.; Pham, X.K.; et al. Susceptibility to Leprosy is Associated with PARK2 and PACRG. Nature 2004, 427, 636-640. [CrossRef]

11. Bragina, E.Y.; Tiys, E.S.; Rudko, A.A.; Ivanisenko, V.A.; Freidin, M.B. Novel Tuberculosis Susceptibility Candidate Genes Revealed by the Reconstruction and Analysis of Associative Networks. Infect. Genet. Evol. 2016, 46, 118-123. [CrossRef]

12. Ali, S.; Vollaard, A.M.; Widjaja, S.; Surjadi, C.; van de Vosse, E.; van Dissel, J.T. PARK2/PACRG Polymorphisms and Susceptibility to Typhoid and Paratyphoid Fever. Clin. Exp. Immunol. 2006, 144, 425-431. [CrossRef]

13. Ichimura, K.; Mungall, A.J.; Fiegler, H.; Pearson, D.M.; Dunham, I.; Carter, N.P.; Peter Collins, V. Small Regions of Overlapping Deletions on 6q26 in Human Astrocytic Tumours Identified Using Chromosome 6 Tile Path Array-CGH. Oncogene 2006, 25, 1261-1271. [CrossRef]

14. Meschede, J.; Šadić, M.; Furthmann, N.; Miedema, T.; Sehr, D.A.; Müller-Rischart, A.K.; Bader, V.; Berlemann, L.A.; Pilsl, A.; Schlierf, A.; et al. The Parkin-coregulated Gene Product PACRG Promotes TNF Signaling by Stabilizing LUBAC. Sci. Signal. 2020, 13, eaav1256. [CrossRef]

15. Li, W.; Walavalkar, N.M.; Buchwald, W.A.; Teves, M.E.; Zhang, L.; Liu, H.; Bilinovich, S.; Peterson, D.L.; Strauss, J.F., 3rd; Williams, D.C., Jr.; et al. Dissecting the Structural Basis of MEIG1 Interaction with PACRG. Sci. Rep. 2016, 6, 18278. [CrossRef]

16. Khan, N.; Pelletier, D.; McAlear, T.S.; Croteau, N.; Veyron, S.; Bayne, A.N.; Black, C.; Ichikawa, M.; Khalifa, A.A.Z.; Chaaban, S.; et al. Crystal Structure of Human PACRG in Complex with MEIG1 Reveals Roles in Axoneme Formation and Tubulin binding. Structure 2021, 29, 1-15.

17. Qing, G.; Ma, L.C.; Khorchid, A.; Swapna, G.V.; Mal, T.K.; Takayama, M.M.; Xia, B.; Phadtare, S.; Ke, H.; Acton, T.; et al. Cold-shock Induced High-yield Protein Production in Escherichia coli. Nat. Biotechnol. 2004, 22, 877-882. [CrossRef]

18. Sugiki, T.; Fujiwara, T.; Kojima, C. Cold-Shock Expression System in E. coli for Protein NMR Studies. Methods Mol. Biol. 2017, 1586, 345-357. [PubMed]

19. Hayashi, K.; Kojima, C. pCold-GST Vector: A Novel Cold-shock Vector Containing GST Tag for Soluble Protein Production. Protein. Expr. Purif. 2008, 62, 120-127. [CrossRef]

20. Lee, D.; Han, S.; Woo, S.; Lee, H.W.; Sun, H.; Kim, W. Enhanced Expression and Purification of Inositol 1,4,5-trisphosphate 3-kinase A through Use of the pCold1-GST Vector and a C-terminal Hexahistidine Tag in Escherichia coli. Protein. Expr. Purif. 2014, 97, 72-80. [CrossRef]

21. Loucks, C.M.; Bialas, N.J.; Dekkers, M.P.; Walker, D.S.; Grundy, L.J.; Li, C.; Inglis, P.N.; Kida, K.; Schafer, W.R.; Blacque, O.E.; et al. PACRG, a Protein Linked to Ciliary Motility, Mediates Cellular Signaling. Mol. Biol. Cell. 2016, 27, 2133-2144. [CrossRef]

22. Shires, S.E.; Quiles, J.M.; Najor, R.H.; Leon, L.J.; Cortez, M.Q.; Lampert, M.A.; Mark, A.; Gustafsson, Å.B. Nuclear Parkin Activates the ERR $\alpha$ Transcriptional Program and Drives Widespread Changes in Gene Expression Following Hypoxia. Sci. Rep. 2020, 10, 8499. [CrossRef] [PubMed]

23. Nezich, C.L.; Wang, C.; Fogel, A.I.; Youle, R.J. MiT/TFE Transcription Factors are Activated during Mitophagy Downstream of Parkin and Atg5. J. Cell Biol. 2015, 210, 435-450. [CrossRef]

24. Ren, Y.; Jiang, H.; Ma, D.; Nakaso, K.; Feng, J. Parkin Degrades Estrogen-related Receptors to Limit the Expression of Monoamine Oxidases. Hum. Mol. Genet. 2011, 20, 1074-1083. [CrossRef]

25. Li, Y.Y.; Yu, H.; Guo, Z.M.; Guo, T.Q.; Tu, K.; Li, Y.X. Systematic Analysis of Head-to-head Gene Organization: Evolutionary Conservation and Potential Biological Relevance. PLoS Comput. Biol. 2006, 2, e74.

26. Shimura, H.; Hattori, N.; Kubo, S.; Mizuno, Y.; Asakawa, S.; Minoshima, S.; Shimizu, N.; Iwai, K.; Chiba, T.; Tanaka, K.; et al. Familial Parkinson Disease Gene Product, Parkin, is a Ubiquitin-protein Ligase. Nat. Genet. 2000, 25, 302-305. [CrossRef] 
27. Tsai, H.C.; Han, M.H. Sphingosine-1-phosphate (S1P) and S1P Signaling Pathway: Therapeutic Targets in Autoimmunity and Inflammation. Drugs 2016, 11, 1067-1079. [CrossRef]

28. Grbčić, P.; Sedić, M. Sphingosine 1-phosphate Signaling and Metabolism in Chemoprevention and Chemoresistance in Colon Cancer. Molecules 2020, 25, 2436. [CrossRef] [PubMed]

29. Gomez-Larrauri, A.; Presa, N.; Dominguez-Herrera, A.; Ouro, A.; Trueba, M.; Gomez-Muñoz, A. Role of Bioactive Sphingolipids in Physiology and Pathology. Essays Biochem. 2020, 64, 579-589. [PubMed]

30. Woo, S.M.; Kwon, T.K. E3 Ubiquitin Ligases and Deubiquitinases as Modulators of TRAIL-mediated Extrinsic Apoptotic Signaling Pathway. BMB Rep. 2019, 52, 119-126. [CrossRef]

31. Stöhr, D.; Jeltsch, A.; Rehm, M. TRAIL Receptor Signaling: From the Basics of Canonical Signal Transduction Toward Its Entanglement with ER Stress and the Unfolded Protein Response. Int. Rev. Cell Mol. Biol. 2020, 351, 57-99.

32. Mazini, P.S.; Alves, H.V.; Reis, P.G.; Lopes, A.P.; Sell, A.M.; Santos-Rosa, M.; Visentainer, J.E.; Rodrigues-Santos, P. Gene Association with Leprosy: A Review of Published Data. Front. Immunol. 2016, 6, 658. [CrossRef]

33. Leturiondo, A.L.; Noronha, A.B.; Mendonça, C.Y.R.; Ferreira, C.O.; Alvarado-Arnez, L.E.; Manta, F.S.N.; Bezerra, O.C.L.; Carvalho, E.F.; Moraes, M.O.; Rodrigues, F.D.C.; et al. Association of NOD2 and IFNG Single Nucleotide Polymorphisms with Leprosy in the Amazon Ethnic Admixed Population. PLoS Negl. Trop. Dis. 2020, 14, e0008247. [CrossRef]

34. Agirre, X.; Román-Gómez, J.; Vázquez, I.; Jiménez-Velasco, A.; Garate, L.; Montiel-Duarte, C.; Artieda, P.; Cordeu, L.; Lahortiga, I.; Calasanz, M.J.; et al. Abnormal Methylation of the Common PARK2 and PACRG Promoter is Associated with Downregulation of Gene Expression in Acute Lymphoblastic Leukemia and Chronic Myeloid Leukemia. Int. J. Cancer 2006, 118, 1945-1953. [CrossRef]

35. Toma, M.I.; Wuttig, D.; Kaiser, S.; Herr, A.; Weber, T.; Zastrow, S.; Koch, R.; Meinhardt, M.; Baretton, G.B.; Wirth, M.P.; et al. PARK2 and PACRG are Commonly Downregulated in Clear-cell Renal Cell Carcinoma and are Associated with Aggressive Disease and Poor Clinical Outcome. Genes Chromosomes Cancer 2013, 52, 265-273. [CrossRef]

36. Han, B.; Yang, X.; Zhang, P.; Zhang, Y.; Tu, Y.; He, Z.; Li, Y.; Yuan, J.; Dong, Y.; Hosseini, D.K.; et al. DNA Methylation Biomarkers for Nasopharyngeal Carcinoma. PLoS ONE 2020, 15, e0230524. [CrossRef]

37. Froes Jr, L.A.R.; Trindade, M.A.B.; Sotto, M.N. Immunology of Leprosy. Int. Rev. Immunol. 2020, 26, 1-21. [CrossRef] [PubMed]

38. Verheul, T.C.J.; van Hijfte, L.; Perenthaler, E.; Barakat, T.S. The Why of YY1: Mechanisms of Transcriptional Regulation by Yin Yang 1. Front. Cell Dev. Biol. 2020, 8, 592164. [CrossRef]

39. Yao, Y.L.; Yang, W.M.; Seto, E. Regulation of Transcription Factor YY1 by Acetylation and Deacetylation. Mol. Cell. Biol. 2001, 21, 5979-5991. [CrossRef]

40. Gordon, S.; Akopyan, G.; Garban, H.; Bonavida, B. Transcription Factor YY1: Structure, Function, and Therapeutic Implications in Cancer Biology. Oncogene 2006, 25, 1125-1142. [CrossRef]

41. Khachigian, L.M. The Yin and Yang of YY1 in Tumor Growth and Suppression. Int. J. Cancer 2018, 143, 460-465. [CrossRef]

42. Krajewska, J.; Arent, Z.; Zolkiewski, M.; Kędzierska-Mieszkowska, S. Isolation and Identification of Putative Protein Substrates of the AAA+ Molecular Chaperone ClpB from the Pathogenic Spirochaete Leptospira interrogans. Int. J. Mol. Sci. 2018, 19, 1234. [CrossRef] [PubMed]

43. Zhang, P.P.; Yan, H.; Yuan, Y.F.; Feng, Y.Q. Searching for Dysbindin-1 Interacting Proteins in Mouse Testis by GST Pull-down and Mass Spectrometry. Chin. J. Biochem. Mol. Biol. 2017, 33, 286-293.

44. Pathan, M.; Keerthikumar, S.; Ang, C.S.; Gangoda, L.; Quek, C.Y.J.; Williamson, N.A.; Mouradov, D.; Sieber, O.M.; Simpson, R.J.; Salim, A.; et al. FunRich: An Open Access Standalone Functional Enrichment and Interaction Network Analysis Tool. Proteomics 2015, 15, 2597-2601. [CrossRef] [PubMed] 